Gingivitis ve hafif-orta şiddette periodontitis hastalarının periodontal, davranışsal ve sistemik durumlarının belirlenmesi

\section{Evaluation of periodontal, behavioral and systemic conditions of patients with gingivitis and mild-moderate periodontitis}

\section{Dr. Öğr. Üyesi Mustafa Yılmaz}

Biruni Üniversitesi, Diș Hekimliği Fakültesi, Periodontoloji A.D., İstanbul

Orcid ID: 0000-0002-2005-1417

\section{Dt. Seyithan Özmen}

Biruni Üniversitesi, Diş Hekimliği Fakültesi, Periodontoloji A.D., İstanbul

Orcid ID: 0000-0001-5083-6015

Dt. Nazlı Gül Kınoğlu

Biruni Üniversitesi, Diş Hekimliği Fakültesi, Periodontoloji A.D., İstanbul Orcid ID: 0000-0002-8289-9093

Doç. Dr. Burcu Karaduman

Biruni Üniversitesi, Diş Hekimliği Fakültesi, Periodontoloji A.D., İstanbul

Orcid ID: 0000-0002-8162-3896

Geliş tarihi: 26 Ağustos 2019

Kabul tarihi: 9 Aralık 2019

doi: 10.5505 /yeditepe.2020.49368

\section{Yazısma adresi: \\ Mustafa Yilmaz}

Biruni Üniversitesi 10. YIl Caddesi Protokol Yolu No: 45 Topkapı 34010 İstanbul -Türkiye

Tel: +905337129952

E-mail: myilmaz@biruni.edu.tr
ÖZET

Amaç: Çalışmamızda gingivitis ile hafif ve orta şiddetli kronik periodontitis vakalarının periodontal ve sistemik durumları ile ağız-diş sağlığı bilinç düzeylerinin ölçülmesi hedeflenmiştir.

Gereç ve Yöntem: Bu retrospektif kesitsel araştırmada Eylül 2017 - Ağustos 2018 tarihleri arasında Biruni Üniversitesi Diş Hekimliği Fakültesi Periodontoloji Anabilim Dalı Kliniği'ne başvuran ve öğrenci kliniğinde tedavi edilmiş olan bireylerin kayıtları değerlendirilmiştir. Bu kayıtlardaki detaylı sistemik anamnezleri, ağız-diş sağlığı farkındalığına ilişkin yanıtları ve radyografik ve klinik parametreleri değerlendirilerek NCSS programıyla istatistiksel ölçümler yapılmıştır.

Bulgular: 685 kadın ve 433 erkek olmak üzere toplam 1118 kişinin kayıtları değerlendirilmiştir. Periodontal hastalıklara göre yaş, cinsiyet, sistemik hastalık, kardiyovasküler hastalık, diyabet, ağız-diş sağlığı bilinç düzeyi anlamlı farklılık göstermekteyken, sigara kullanımı, sindirim sistemi hastalıkları, romatolojik hastalıklar ve psikiyatrik bozukluklar açısından anlamlı bir farklılık saptanmamıştır.

Sonuç: Bireylerin periodontal tabloları ile davranışsal ve sistemik durumları arasında hastalığın şiddeti ve süresiyle bağlantılı bir ilişki vardır.

Anahtar kelimeler: Periodontitis, gingivitis, sigara, sistemik hastalık, bilinç

\section{SUMMARY}

Aim: The aim of our study is to evaluate the periodontal and systemic conditions and oral health awareness of cases with gingivitis and mild or moderate chronic periodontitis.

Materials and Methods: In this retrospective cross-sectional study, the records of individuals who applied to the Department of Periodontology of Biruni University Faculty of Dentistry between September 2017 and August 2018 were evaluated. In these records, the patients' detailed medical history, their responses to questions about oral health awareness and their radiographic and clinical parameters were evaluated. The statistical measurements were made with the NCSS program.

Results: The records of 1118 people, 685 women and 433 men, were evaluated. While age, sex, systemic condition, cardiovascular disease, diabetes and oral health awareness level differed significantly according to periodontal condition no significant difference was found in terms of smoking, digestive system disorders, rheumatologic diseases and psychiatric disorders.

Conclusion: There is a relationship between the periodontal condition of individuals and their behavioral and systemic conditions related to the severity and to the duration of the disease.

Keywords: Periodontitis, gingivitis, smoking, systemic 
disease, awareness

\section{GíRiş}

Periodontitis, klinik ataşman kaybı ve kemik yıkımı izlenen enfeksiyöz karakterde enflamatuvar bir hastalıktır. Hastalığın primer etyolojik ajanı mikrobiyal dental plak olmasına rağmen, birçok hazırlayıcı etken ve risk faktörü tabloyu etkilemektedir. ${ }^{1}$ Yaş, cinsiyet, ailesel geçiş, sistemik durum, ağız bakım alışkanlığı gibi genetik, çevresel ve diğer modifiye edici faktörler sağlık durumundan hastalığa geçişe neden olan bir patern içerisinde rol almaktadır. ${ }^{2}$ Ataşman ve kemik kaybı görülmeyen ve reversibl olan gingivitis tablosundan periodontitise dönüşüm, konak yanıtını etkileyen bu faktörler eşliğinde gerçekleşir. Bununla beraber, yeni bilgiler ışığında, periodontitisin duyarlı konaklarda ve her üyesinin farklı belirgin rolleri olan polimikrobiyal bir topluluk tarafından indüklendiği, aynı zamanda bazı patojenlerin konak yanıtını değiştirerek disbiyotik bir mikrobiyotaya neden olduğu düşünülmektedir. Buradaki patobiyontlar, enflamatuvar yanıtı aşırı şekilde aktive ederek periodontal doku yıkımına neden olmaktadırlar. ${ }^{3}$

Yıkım şiddetine göre periodontitisler hafif (1-2 mm klinik ataşman kaybı), orta (3-4 $\mathrm{mm}$ ) ve şiddetli $(5 \mathrm{~mm})$ olarak sınıflandırımaktadır. Lokalizasyona göre ise kronik periodontitisler, alanların \%30'undan fazlasının etkilenmesi durumunda generalize, daha az alanda tutulum varsa lokalize olarak tanımlanmıştır. ${ }^{4}$

Periodontal dokuların sağlığı, ağız-diş sağlığı farkındalığı ve bağlantılı şekilde doğru ağız bakım uygulamalarıyla doğrudan ilişkilidir. Bununla beraber periodontitisin sigara, diyabet, romatoid artrit, kardiyovasküler hastalıklar, obezite gibi enflamatuvar sürece etki eden veya bu süreçten etkilenen sistemik durumlar ile ilişkili olduğuna dair birçok kanıt mevcuttur. ${ }^{5}$ Bu hastalıklar ile periodontitis arasında ortak risk faktörleri olduğu gibi, oluşturdukları sistemik enflamasyon aracılığı ile birbirlerini etkileyebildikleri düşünülmektedir.6 Periodontitise duyarlı bireylerdeki oksidatif stresin orijininin bakteriyel lipopolisakkaritlerin neden mitokondriyal disfonksiyon olduğu ve bunun kardiyovasküler olaylar ve periodontitis gibi hastalıklar açısından olası bir bağlantı olabileceği önerilmiştir. ${ }^{6}$ Periferik kan mononükleer hücrelerinin oksidatif stresi artırdığı ve sitokin homeostazını değiştirdiği düşünülmektedir. ${ }^{6}$ Bilindiği üzere periodontitiste patojenlere karşı konakta immunoenflamatuvar yanıt gerçekleşmekte ve proenflamatuvar sitokinler, prostanoidler ve matriks metalloproteinazlar gibi moleküller bağ doku ve kemik metabolizmasını değiştirmektedirler. ${ }^{2}$ Buna bağlı olarak plazma fibrinojen ve dolaşımdaki akut faz reaktanlarının arttığı ve bunun artmış kardiyovasküler risk ile ilişkili olduğu gösterilmiştir. ${ }^{7}$ Sistemik durum ve periodontal hastalıklar arasındaki mekanizmayı açığa çıkarmak için birçok araştırma yapılması- na rağmen komorbidite çalışmaları sınırlı sayıdadır. ${ }^{8}$ Bu çalışma, öğrenci kliniğinde tedavileri yürütülmüş olan gingivitis ile hafif ve orta şiddetli kronik periodontitis vakalarının periodontal parametreleri, ağız-diş sağlığı bilinç düzeyleri, sigara kullanımları ve sistemik durumlarının saptanmasını hedeflemektedir.

\section{GEREÇ VE YÖNTEM}

Bu retrospektif kesitsel araştırma, Dünya Tıp Birliği Helsinki Bildirgesi'nde belirtilen etik ilkeler çerçevesinde planlanmış ve Biruni Üniversitesi Girişimsel Olmayan Klinik Araştırmalar Etik Kurulu'nun 2018/20-15 sayılı kararı ile onaylanmıştır. Çalışmaya katılan tüm bireylerden bilgilendirilmiş onam alınmıştır.

Eylül 2017-Ağustos 2018 tarihleri arasında Biruni Üniversitesi Diş Hekimliği Fakültesi Periodontoloji Anabilim Dalı Kliniği'ne başvuran ve öğrenci kliniğinde tedavi edilmiş olan bireylerin kayıtları değerlendirilmiştir. Şiddetli periodontal yıkım görülen (klinik ataşman kaybı $\geq 5 \mathrm{~mm}$ ) ve dişeti büyümesi, onarılabilir dişeti çekilmesi gibi faz II tedaviyi gerektirecek durumu olan bireyler, tedavileri öğretim üyesi kliniğinde sürdürüldüğü için çalışmaya dâhil edilmemiştir.

Tüm bireylerden detaylı sistemik anamnez alınmış ve bireylere ağız-diş sağlığı farkındalığını ölçmeye yönelik önceden belirlenmiş sorular yöneltilmiştir (Tablo 2). Klinik muayene sırasında Williams tipi standart periodontal sonda kullanılarak, Ramfjord indeks dişlerinden ${ }^{9}$ ve her dişin 6 bölgesinden olmak üzere, Silness-Löe plak indeksi $(\mathrm{Pi})^{10}$ ve Löe-Silness gingival indeks (Gi) ${ }^{11}$ skorları elde edilmiştir. Tüm dişlerin 6 bölgesinde sondalama derinlikleri (SD) ölçülmüştür. Bireyler, klinik ve radyografik parametreler değerlendirilerek 1999 Periodontal Hastalık ve Durumların Sınıflandırması'na göre teşhis edilmiştir. ${ }^{4}$ Istatistiksel Analiz

İstatistiksel analiz için NCSS (Number Cruncher Statistical System; 2007, Kaysville, Utah, USA) programı kullanılmıştır. Tanımlayıcı istatistiksel metotlar, niceliksel veriler ve normal dağılım gösteren değişkenlerin iki grup arası karşılaştırmalarında Student t Test, normal dağılım göstermeyen değişkenlerin iki grup karşılaştırmalarında ise Mann Whitney U testi tercih edilmiştir. Normal dağılım gösteren üç ve üzeri sayıda grubun karşılaştırmalarında Oneway Anova Test ve ikili karşılaştırmalarında Bonferroni Test; normal dağılım göstermeyen üç ve üzeri sayıda grubun karşılaştırmalarında ise Kruskal Wallis ve ikili karşılaştırmalarında Bonferroni-Dunn Test kullanılmıştır. Değişkenler arası ilişkilerin değerlendirilmesinde Pearson Korelasyon Analizi ve Spearman's Korelasyon Analizi, niteliksel verilerin karşılaştırılmasında ise Pearson KiKare testi ve Fisher-Freeman-Halton Testi kullanılmıştır. $p<0,05$, anlamlı olarak değerlendirilmiştir.

\section{BULGULAR}

Çalışmamızda \%61,3'ü (n=685) kadın, \%38,7'si (n=433) 
erkek olmak üzere toplam 1118 kişinin kayıtları değerlendirilmiştir. Bu bireylere ait demografik veriler, sistemik tablo ve sigara kullanımının dağılımı, Tablo 1'de görüldüğü gibidir.

Tablo 1. Demografik veriler ve sistemik durumun dağııımı

\begin{tabular}{|c|c|c|c|c|c|}
\hline & Kadın & Erkek & Toplam & \multirow{2}{*}{ p } \\
\hline & & n (\%) & n (\%) & $N(\%)$ & \\
\hline \multirow{7}{*}{$\begin{array}{l}\text { Yas } \\
\text { (yil) }\end{array}$} & $\begin{array}{l}\text { Min-Maks } \\
\text { (Medyan) }\end{array}$ & 9-77 (34) & $10-76(34)$ & 9-77 (34) & \multirow{7}{*}{${ }^{a} 0,168$} \\
\hline & $O r t \pm S s$ & $34,34 \pm 13,43$ & $35,51 \pm 14,32$ & $34,79 \pm 13,79$ & \\
\hline & $\leq 24$ yaş & $223(32,6)$ & $129(29,8)$ & $352(31,5)$ & \\
\hline & 25-34 yaş & $142(20,7)$ & $91(21,0)$ & $233(20,8)$ & \\
\hline & 35-44 yaş & $162(23,6)$ & $100(23,1)$ & $262(23,4)$ & \\
\hline & 45-64 yaş & $147(21,5)$ & $99(22,9)$ & $246(22,0)$ & \\
\hline & $\geq 65$ yaş & $11(1,6)$ & $14(3,2)$ & $25(2,2)$ & \\
\hline \multicolumn{2}{|c|}{ Sigara kullanımı } & $153(22,3)$ & $163(37,6)$ & $316(28,3)$ & ${ }^{b} 0,001^{* * *}$ \\
\hline \multicolumn{2}{|c|}{ Sistemik hastalık } & $164(23,9)$ & $69(15,9)$ & $233(20,8)$ & ${ }^{b} 0,001$ ** \\
\hline \multicolumn{2}{|c|}{$\begin{array}{l}\text { Kalp damar } \\
\text { hastalıkları }\end{array}$} & $66(9,6)$ & $30(6,9)$ & $96(8,6)$ & ${ }^{b} 0,116$ \\
\hline \multicolumn{2}{|c|}{ Hipertansiyon } & $40(5,8)$ & $15(3,5)$ & $55(4,9)$ & ${ }^{b} 0,074$ \\
\hline \multicolumn{2}{|c|}{$\begin{array}{l}\text { Sindirim sistemi } \\
\text { hastalıkları }\end{array}$} & $67(9,8)$ & $24(5,5)$ & $91(8,1)$ & ${ }^{b} 0,012^{*}$ \\
\hline \multicolumn{2}{|c|}{$\begin{array}{l}\text { Psikiyatrik } \\
\text { bozukluk }\end{array}$} & $24(3,5)$ & $6(1,4)$ & $30(2,7)$ & ${ }^{b} 0,033^{*}$ \\
\hline \multicolumn{2}{|c|}{$\begin{array}{l}\text { Romatolojik } \\
\text { hastalık }\end{array}$} & $17(2,5)$ & $5(1,2)$ & $22(2,0)$ & ${ }^{b} 0,120$ \\
\hline \multicolumn{2}{|c|}{ Diyabet } & $23(3,4)$ & $13(3,0)$ & $36(3,2)$ & ${ }^{b} 0,743$ \\
\hline
\end{tabular}

Kadın ve erkek olguların yaş gruplarına göre dağılımlarında istatistiksel olarak anlamlı farklılık saptanmamıştır $(p>0,05)$. Sigara içen erkek birey sayısı kadınlara kıyasla anlamlı derecede fazladır $(p=0,001)$. Bununla birlikte kadınlarda teşhisi konulmuş sistemik hastalık $(p=0,001)$, sindirim sistemi hastalığı $(p<0,05)$ ve psikiyatrik bozukluk $(p<0,05)$ görülme oranı erkeklere göre anlamlı derecede yüksektir. Cinsiyete göre kalp damar hastalıkları, hipertansiyon, romatolojik hastalık ve diyabet varlığı istatistiksel olarak anlamlı fark göstermemektedir $(p>0,05)$.

Periodontal indekslerin ortalamaları alınarak elde edilen veriler ve periodontal duruma göre dağıım Tablo 2 'de görüldüğü gibidir.

Tablo 2. Periodontal durum ve bilinç düzeyi

\begin{tabular}{|c|c|c|c|c|c|c|}
\hline & & & Kadın (\%) & Erkek (\%) & n (\%) & \\
\hline & "Gingivitis/sağlıklı & & $437(63,7)$ & $\begin{array}{l}244(56,4) \\
\end{array}$ & $\bar{~} 6881(60,9)$ & $\overline{b^{b}, 038^{*}}$ \\
\hline & Lokalize periodontitis & & $99(14,5)$ & $70(16,2)$ & $169(15,1)$ & \\
\hline & Generalize periodontiti & & $149(21,8)$ & $119(27,5)$ & $268(24,0)$ & \\
\hline & Min-Maks (Medyan) & & $0-3(1,2)$ & $0-3(1,4)$ & $0-3(1,3)$ & ${ }^{a} 0,001^{* *}$ \\
\hline & $O r t \pm S s$ & & $1,28 \pm 0,57$ & $1,44 \pm 0,58$ & $1,34 \pm 0,58$ & \\
\hline$C^{\circ}$ & Min-Maks (Medyan) & & $0-3(1,1)$ & $0-3(1,2)$ & $0-3(1,2)$ & ${ }^{a} 0,039$ " \\
\hline & Ort $\pm S s$ & & $1,11 \pm 0,60$ & $1,19 \pm 0,61$ & $1,14 \pm 0,60$ & \\
\hline & Min-Maks (Medyan) & & $0,2-5,2(1,9)$ & $0,4-5,2(2,1)$ & $0,2-5,2(2)$ & ${ }^{a} 0,001^{\text {** }}$ \\
\hline & Ort $\pm S s$ & & $1,95 \pm 0,64$ & $2,13 \pm 0,67$ & $2,02 \pm 0,66$ & \\
\hline & mayı biliyor & Hayir & $196(28,6)$ & $132(30,5)$ & $328(29,3)$ & ${ }^{b} 0,503$ \\
\hline & & Evet & $489(71,4)$ & $301(69,5)$ & $790(70,7)$ & \\
\hline & diș yüzeyi temizliği & Hayır & $317(46,3)$ & $214(49,4)$ & $531(47,5)$ & ${ }^{b} 0,305$ \\
\hline & mi?" & Evet & $368(53,7)$ & $219(50,6)$ & $587(52,5)$ & \\
\hline & erken yaşta dişlerini & Yok & $479(69,9)$ & $330(76,2)$ & $809(72,4)$ & ${ }^{b} 0,022^{*}$ \\
\hline & r var mı?" & Var & $206(30,1)$ & $103(23,8)$ & $309(27,6)$ & \\
\hline & is tedavisi surasinda & Hayir & $651(95,0)$ & $414(95,6)$ & $1065(95,3)$ & ${ }^{b} 0,659$ \\
\hline & dinzz mı?" & Evet & $34(5,0)$ & $19(4,4)$ & $53(4,7)$ & \\
\hline
\end{tabular}

Erkeklerde plak indeksi $(p=0,001)$, gingival indeks $(p<0,05)$ ve cep derinliklerinin $(p=0,001)$ ortalamalarının kadınlara göre anlamlı derecede yüksek olduğu saptanmıştır. Yine erkeklerde periodontitis görülme sıklığı kadınlara göre daha fazladır $(p<0,05)$.

Hastaların ağız-diş sağlığı ile ilgili bilinç düzeylerini ölçmek amacıyla yöneltilen sorular ve yanıtların dağılımı Tablo 2'te izlenmektedir. Kadın olguların ailelerinde erken diş kaybetme oranı erkeklere göre istatistiksel olarak anlamlı düzeyde yüksektir ( $p<0,05 ; p<0,05)$. Bunun dışındaki ağız-diş sağlığı farkındalığına yönelik soruların yanıtları cinsiyetler arasında farklıık göstermemektedir $(p>0,05)$. Çalışmaya katılan bireylerin periodontal hastalıklarının tanısı ile yaş ve sistemik durumları arasındaki ilişki Tablo 3 'te izlendiği gibidir.

Tablo 3. Periodontal hastalıklar ve sistemik tablonun dağıımı

\begin{tabular}{|c|c|c|c|c|c|}
\hline & & \multicolumn{3}{|c|}{ Periodontal hastalık } & \multirow{3}{*}{$p$} \\
\hline & & $\mathrm{G}(\mathrm{n}=681)$ & LP $(n=169)$ & GP $(n=268)$ & \\
\hline & & n (\%) & n (\%) & n (\%) & \\
\hline \multirow{7}{*}{ Yaș (yıl) } & $\begin{array}{l}\text { Min-Mak } \\
\text { (Medyan) }\end{array}$ & $9-72(26)$ & $12-76(38)$ & $17-77(45)$ & \multirow[t]{2}{*}{${ }^{d} 0,001^{* * *}$} \\
\hline & $O r t \pm S s$ & $29,57 \pm 11,99$ & $39,18 \pm 12,21$ & $45,31 \pm 11,95$ & \\
\hline & $\leq \mathbf{2 4}$ yaş & $318(46,7)$ & $23(13,6)$ & $11(4,1)$ & \\
\hline & 25-34 yaș & $157(23,1)$ & $39(23,1)$ & $37(13,8)$ & \\
\hline & $35-44$ yaş & $125(18,4)$ & $52(30,8)$ & $85(31,7)$ & \\
\hline & 45-64 yaş & $75(11,0)$ & $52(30,8)$ & $119(44,4)$ & \\
\hline & $\geq 65$ yaş & $6(0,9)$ & $3(1,8)$ & $16(6,0)$ & \\
\hline \multicolumn{2}{|c|}{ Sigara kullanımı } & $180(26,4)$ & $48(28,4)$ & $88(32,8)$ & ${ }^{b} 0,143$ \\
\hline \multicolumn{2}{|c|}{ Sistemik hastalık } & $115(16,9)$ & $37(21,9)$ & $81(30,2)$ & ${ }^{b} 0,001^{* *}$ \\
\hline \multicolumn{2}{|c|}{ Kalp damar hastalıkları } & $36(5,3)$ & $16(9,5)$ & $44(16,4)$ & ${ }^{b} 0,001 * *$ \\
\hline \multicolumn{2}{|c|}{ Hipertansiyon } & $19(2,8)$ & $8(4,7)$ & $28(10,4)$ & ${ }^{b} 0,001 * *$ \\
\hline \multicolumn{2}{|c|}{ Sindirim sistemi hastalıkları } & $57(8,4)$ & $13(7,7)$ & $21(7,8)$ & ${ }^{b} 0,939$ \\
\hline \multicolumn{2}{|c|}{ Psikiyatrik hastalık } & $16(2,3)$ & $5(3,0)$ & $9(3,4)$ & ${ }^{e} 0,582$ \\
\hline \multicolumn{2}{|c|}{ Romatolojik hastalık } & $11(1,6)$ & $3(1,8)$ & $8(3)$ & ${ }^{e} 0,353$ \\
\hline \multicolumn{2}{|l|}{ Diyabet } & $14(2,1)$ & $5(3,0)$ & $17(6,3)$ & ${ }^{b} 0,003^{* * *}$ \\
\hline
\end{tabular}

Buna göre, generalize periodontitisi (GP) olan bireylerin yaşları, gingivitis $(G)(p=0,001)$ ve lokalize peridontitis (LP) $(p=0,001)$ gruplarından yüksektir. Benzer şekilde, LP'li bireylerin gingivitis grubuna göre daha ileri yaşta olduğu izlenmektedir $(p=0,001)$. Peridontal durumun dağılımı ve sigara kullanma oranları arasında istatistiksel bir ilişki saptanmamıştır ( $p>0,05)$. Çalışmaya katılan ve sistemik hastalığı olan bireylerde periodontitis görülme sıklığı fazladır ( $p=0,001)$. Yine GP grubunda kalp damar hastalığı görülme oranı G ve LP gruplarına göre, LP grubunda ise G'ye göre yüksektir. Hipertansiyon oranı, GP grubunda G ve LP'ye göre daha yüksektir. Sindirim sistemi hastalıkları, psikiyatrik hastalık ve romatolojik hastalık görülme sıklığı gruplar arasında istatistiksel olarak anlamlı farklıık göstermemektedir $(p>0,05)$. GP grubunda diyabet G'ye göre anlamlı derecede sık izlenmektedir $(p<0,01)$.

Periodontal indeksler incelendiğinde, GP grubunun PI 
ölçümlerinin, $G(p=0,001)$ ve LP $(p=0,001)$ gruplarından yüksek olduğu gözlenmiştir $(p<0,01)$. Benzer şekilde LP'nin PI skorları G grubundan yüksektir $(p<0,01$; $p<0,01) .24$ yaş ve altındaki olgularda Pi, 35-44, 45-64 ve 65 yaş ve üzeri bireylere göre anlamlı derecede daha düşüktür $(p<0,001)$. Bununla birlikte yaş ile plak indeksi ortalamaları arasında pozitif yönlü çok zayıf anlamlı ilişki mevcuttur ( $r: 0,185 ; p=0,001)$. Pl, sigara içmeyen

bireylerde içenlere göre $(p<0,05)$ ve diş fırçalamayı bildiğini ifade edenlerde bilmediğini söyleyenlere göre $(p=0,001)$ daha düşük olarak saptanmıştır. Kalp

damar hastalığı bulunan $(p<0,05)$ ve diyabetik

bireylerde $(p<0,05)$ skorlar yüksek, sindirim sistemi bozukluğu olanlarda ise $(p<0,05)$ anlamlı derecede düşük olarak saptanmıştır. GP grubunun Gi ölçümleri, G $(p=0,001)$ ve LP $(p=0,001)$ gruplarından yüksek bulunmuştur $(p<0,01)$. LP grubu Gi skorları $G$ grubundan yüksektir $(p<0,01)$. Plak indeksine paralel olarak 24 yaş ve altındaki olguların kanama indeksleri 35-44, 45-64 ve 65 yaş ve üzeri olgulara göre daha düşüktür $(p<0,05, p=0,001$, $p<0,01)$. Yaş ile Gi ölçümleri arasında pozitif yönlü $\% 18,7$ düzeyindeki çok zayıf ilişki, istatistiksel olarak anlamlı bulunmuştur ( $r: 0,187 ; p=0,001)$. Sigara kullanımına göre Gi ölçümleri arasında istatistiksel olarak anlamlı farklılık saptanmamıștır $(p>0,05)$. Kalp damar hastalığı bulunan olgularda $(p<0,05)$ ve ailede erken diş kaybı görülenlerde $(p<0,05)$ Gi skorları anlamlı derecede yüksek, diş fırçalamayı bilen olgularda ise düşük $(p<0,01)$ olarak belirlenmiştir. GP grubunun sondalama derinliği skorları $G$ $(p=0,001)$ ve LP $(p=0,001)^{\prime} y e$, LP grubunun ise G'ye göre yüksektir ( $p=0,001)$. Yine 24 yaş ve altındaki olguların $S D$ skorları 25-34 yaş; 35-44 yaş; $45-64$ yaş ve 65 yaş ve üzeri olgulardan istatistiksel olarak anlamlı düzeyde düşük olarak saptanmıştır $(p=0,01 ; p=0,001 ; p=0,001 ; p=0,001)$. Yaş ile SD arasında pozitif yönlü \%28,4 düzeyindeki zayıf ilişki istatistiksel olarak anlamlıdır ( $r: 0,284 ; p=0,001)$. Kalp damar hastalığı $(p=0,001)$ ve hipertansiyonu $(p<0,05)$ olan hastalarda SD görece yüksek, sindirim sistemi bozukluğu olanlarda ise $(p<0,05)$ düşük olarak saptanmıştır. Diş fırçalamayı bilen bireylerde ceplerin daha sığ olduğu görülmektedir $(p=0,001)$. Diğer parametreler anlamlı fark göstermemektedir $(p>0,05)$.

GP'li bireylerde diş fırçalama farkındalığının oranı, diğer gruplardan düşük bulunmuştur $(p=0,001)$. Yine $G P$ grubunda, ailede erken diş kaybı hikâyesi varlığı G'ye göre fazladır $(p<0,05)$. Daha önce diş yüzeyi temizliği yaptırmış olmak veya dental tedavi sırasında sorun yaşanmış olması açısından gruplar arasında istatistiksel anlamlı bir ilişki saptanmamıştır ( $p>0,05)$.

\section{TARTIȘMA}

Periodontitis ile sistemik enflamatuvar hastalıklar arasında çift yönlü bir ilişki olduğu düşünülmektedir., ${ }^{2,16} \mathrm{Bu}$ nedenle, periodontitis ile birlikte seyreden sistemik hastalıkların saptanması önem arz etmektedir. Çalışmamıza katılan gingivitis veya hafif - orta şiddette periodontitis tanısı konulmuş toplam 1118 bireyin 233'ünde $(\% 20,8)$ en az bir veya daha fazla sistemik hastalık veya bozukluk izlenmiştir. Bu değer, Akpınar ve ark. $(\% 39,2)$ ve Kodalak ve ark. $(\% 41,6)$ çalışmalarına göre nispeten düşüktür. ${ }^{12,13}$ Bunu ileri şiddette periodontitis vakalarının araştırmaya dâhil edilmemiş olmasına bağlamak mümkündür. Elde ettiğimiz sonuçlara göre, literatür ile uyumlu olarak, sistemik hastalığı olan bireylerde periodontitis görülme sıklığının daha yüksek olduğu görülmektedir. ${ }^{14}$

Saptanan sistemik hastalıkların önemli bir kısmını kalp-damar hastalıkları $(\% 8,6)$ oluşturmaktadır. Kardiyovasküler hastalıklar $(\mathrm{KVH})$ prevalansı üzerine yapılan çalışmalarda Türk erkeklerinin yaklaşık \%5,8'i ile kadınlarının \%5'inde KVH görüldüğü ve prevalansın artmakta olduğu gösterilmiştir. ${ }^{15,16}$ Bununla beraber KVH için önemli bir risk faktörü teşkil eden hipertansiyon prevalansı Türk toplumunda $\% 31,8$ oranında belirlenmiştir. ${ }^{17}$ Çalışmamıza katılan bireylerin \%4,9'u hipertansif olduğunu belirtmiştir ve bu bireylerde generalize periodontitis görülme oranı yüksektir. Bu prevalans farkı, genç denek sayısının yüksek olmasından ya da gizli olgulardan kaynaklanıyor olabilir. Elde ettiğimiz verilere göre periodontitisli bireylerde KVH görülme sıklığı yıkım görülmeyen bireylere göre fazladır. Aynı şekilde KVH'si olanlarda plak ve gingival indeks skorları nispeten yüksektir.

Periodontitis ve miyokard infarktüsü, inme, KVH gibi aterosklerotik vasküler hastalıklar arasındaki ilişki birçok prospektif kohort ve vaka kontrol çalışması ile açığa çıkarılmıştır ve bulgularımız bu bilgiler ile uyumludur. ${ }^{18}$ Daha önce yapılan çalışmalarda ülseratif kolit ve Crohn hastalığına sahip bireylerde periodontitis görülme oranının yüksek olduğu ve ilişkide sigaranın önemli bir rol oynadığı gösterilmiştir. ${ }^{19}$ Araştırmamızda detaylı sorgulamaya yetecek sayıda ülseratif kolit/Crohn olgusu olmadığı için reflü, mide ülseri gibi farklı etyolojik nedenlere bağlı olarak gelişen tüm sindirim sistemi hastalıkları havuzlanmıştır. Sonuç olarak periodontal tablo ve sindirim sistemi bozuklukları arasında istatistiksel anlamlı bir ilişki saptanmamıştır. Benzer şekilde havuzlanan romatolojik hastalıklar ve psikiyatrik bozukluklar ile periodontal tablo ilişkili bulunmamıştır. Romatoid artrit ile periodontitisin diş kaybı, klinik ataşman kaybı ve eritrosit

sedimentasyonu açısından bağlantılı olduğuna dair yeterince kanıt olmasına rağmen klinik ilişki ve bu ilişkinin biyokimyasal mekanizmasının aydınlatılması gerektiği önerilmektedir. ${ }^{20}$ Psikiyatrik bozukluklar ile periodontal tablo arasındaki bağlantıya ilişkin ise henüz netlik yoktur. Stres periodontitis için önemli bir risk faktörü olarak kabul edilmektedir. ${ }^{1}$ Ancak yapılan bir meta-analize göre depresyon ve periodontitis arasında anlamlı bir ilişki bulunmamıştır. ${ }^{21}$ 
Diyabet ile periodontal hastalıklar arasındaki çift yönlü ilișki ve bu ilişkinin arkasındaki muhtemel enflamatuvar mekanizma iyi şekilde tanımlanmıştır. ${ }^{22}$ Dünya sağlık örgütü verilerine göre toplam nüfusun $\% 8,5^{\prime}$ inde diyabet gözlenmekteyken başta Afrika ülkelerinde olmak üzere, diyabetik bireylerin neredeyse yarısının durumlarından haberdar olmadıkları düşünülmektedir. ${ }^{22}$ Çalışmamıza katılan bireylerin \%3,2'si tanısı konulmuş diyabet hastasıdır ve bu bireylerde plak indeksi skorları ve periodontitis teşhis oranı yüksektir. Bu durum, diyabetik bireylerde oral hijyenin daha zayıf olduğu ve diyabetin periodontitis başlangıç ve ilerleyiş hızı riskini artırdığına dair bilgilerimizle uyumludur. ${ }^{23}$

Elde ettiğimiz veriler içerisinde tartışmaya en açık bulgu, sigara kullanan bireylerde plak indeksi skorunun daha yüksek olmasına rağmen periodontitis tablosu ile aralarında bir ilişki saptanmamış olmasıdır. Yapılan çalışma ve meta-analizlere göre sigara ataşman kaybı, dişeti çekilmesi miktarı, periodontal hastalığın ilerleyiş hızı ve diş kaybını artırmakla beraber özellikle orta ve şiddetli periodontitis prevalansını artırmaktadır. ${ }^{24}$ Aynı zamanda sigara kullanımının periodonsiyuma etkilerinde bir doz - yanıt ilişkisi olduğu gösterilmiştir. ${ }^{25}$ Buna alternatif bir yorum, Faddy ve arkadaşlarının 504 denekte yaptıkları bir longitudinal çalışmanın sonuçlarındadır. Buna göre sigara kullanımı ve yaş, hastalık ilerleyişine bir etki etmezken iyileşme sürecini bozarak hastalığın regresyonunu azaltmaktadır. ${ }^{26}$ Çalışmamızda değerlendirilen olguların $\% 46,7$ 'si gibi büyük bir rakamın 24 yaş ve altında olmasının ve bağlantılı şekilde sigaranın kümülatif etkilerinin nispepen az olmasının, aynı zamanda değerlendirmeye alınan bireylerin hafif-orta şiddetli periodontitis vakaları olmalarının sonuca etkisi olabileceği kanısındayız.

Periodontal tedavinin bir basamağı olan ağız-diş sağlığı farkındalığı ve oral hijyen alışkanlığının düzeltilmesi hastalık seyrinde ve hayat kalitesinin artırılmasında önemli bir rol oynamaktadır. ${ }^{27}$ Çalıșmamızda, kronik periodontitisli bireylerde diş fırçalama farkındalığının daha düşük ve aile hikâyesinin daha yüksek oranda olduğu, aynı zamanda, diş fırçalamayı bilenlerde plak indeksi, gingival indeks ve cep derinliği parametrelerinin daha düşük olduğu gözlemlenmiştir. Elde ettiğimiz verilere göre, mevcut bilgiler ile uyumlu olarak kadınlarda ağız bakım alışkanlığının nispeten daha iyi olduğunu ve daha az periodontal yıkım görüldüğünü söylemek mümkündür. ${ }^{28}$

\section{SONUÇ}

Çalışmamızda yaş, cinsiyet, sistemik hastalık varlığı, diyabet, kardiyovasküler hastalık, ağız-diş sağlığı farkındalığı ve aile hikâyesinin hafif-orta şiddette periodontitis ile ilişkili olduğu saptanmıştır. Hastaların periodontal hastalık ile sistemik tablo arasındaki ilişki konusunda bilgilendirilmeleri ve ağız bakımı alışkanlıklarının neden-sonuç ilişkisi ortaya konularak geliştirilmesi önem arz etmektedir.

\section{KAYNAKLAR}

1. Genco RJ, Borgnakke WS. Risk factors for periodontal disease. Periodontol 2000 2013; 62:59-94.

2. Kornman KS. Mapping the pathogenesis of periodontitis: a new look. J Periodontol 2008; 1560-8.

3. Hajishengallis G. Periodontitis: from microbial immune subversion to systemic inflammation. Nat Rev Immunol. 2015; 15:30-44.

4. Armitage GC. Development of a classification system for periodontal diseases and conditions. Ann Periodontol. 1999; 4:1-6.

5. Brown LJ, Löe H. Prevalence, extent, severity and progression of periodontal disease. Periodontol 2000 1993; 2:57-71.

6. Flemmig TF. Periodontitis. Ann Periodontol. 1999; 4:32-8.

7. Bullon $\mathrm{P}$, Newman HN, Battino M. Obesity, diabetes mellitus, atherosclerosis and chronic periodontitis: a shared pathology via oxidative stress and mitochondrial dysfunction? Periodontol 2000. 2014; 64:139-53.

8. Holmstrup P, Damgaard C, Olsen I, Klinge B, Flyvbjerg A ve ark. Comorbidity of periodontal disease: two sides of the same coin? An introduction for the clinician. J Oral Microbiol. 2017; 9:1332710.

9. Ramfjord, S. P. Indices for Prevalence and Incidence of Periodontal Disease. The Journal of Periodontology. 1959; 30: 51-59.

10. Silness J, Loe H. Periodontal disease in pregnancy. II. Correlation between oral hygiene and periodontal Condition. Acta Odontol Scand 1964; 22: 121-35.

11. Loe $\mathrm{H}$, Silness J. Periodontal disease in pregnancy. I. Prevalence and severity. Acta Odontol Scand 1963; 21:533-51.

12. Demir Kodalak S, Öztürk Özener H, Ağralı O, Yıldırım $S$, Kuru L. Periodontal and systemic health conditions of the patients treated in the student clinic of department of periodontology between the years 2012-2014. Yeditepe J Dent 2018; 14: 55-62.

13. Akpınar $A$, Toker $H$, Çalışır M. Periodontoloji kliniğine başvuran hastalarda periodontal durum ve sistemik hastalıkların değerlendirilmesi. Cumhuriyet Dent J 2012; 15: 93-100.

14. Lagervall M, Jansson L, Bergström J. Systemic disorders in patients with periodontal disease. J Clin Periodontol 2003; 30: 293-9.

15. Onat A, Senocak MS, Surdum-Avci G, Ornek E. Prevalence of coronary heart disease in Turkish adults. Int $J$ Cardiol 1993; 39:23-31.

16. Balbay $Y$, Gagnon-Arpin I, Malhan S, Öksüz ME, Sutherland $G$ ve ark. Modeling the burden of cardiovascular disease in Turkey. Anatol J Cardiol 2018; 20:235240.

17. Arici M, Turgan C, Altun B, Sindel S, Erbay B ve ark. 
Turkish Society of Hypertension and Renal Diseases. Hypertension incidence in Turkey (HinT): a population-based study. J Hypertens 2010; 28:240-244.

18. Stewart R, West M. Increasing Evidence for an Association Between Periodontitis and Cardiovascular Disease. Circulation 2016; 133:549-551.

19. Brito F, de Barros FC, Zaltman C, Carvalho AT, Carneiro AJ ve ark. Prevalence of periodontitis and DMFT index in patients with Crohn's disease and ulcerative colitis. $J$ Clin Periodontol 2008; 35:555-60.

20. de Pablo P, Chapple IL, Buckley CD, Dietrich T. Periodontitis in systemic rheumatic diseases. Nat Rev Rheumatol 2009; 5: 218-24.

21. Araújo MM, Martins CC, Costa LC, Cota LO, Faria RL ve ark. Association between depression and periodontitis: a systematic review and meta-analysis. J Clin Periodontol 2016; 43:216-28.

22. Kocher T, König J, Borgnakke WS, Pink C, Meisel P. Periodontal complications of hyperglycemia/diabetes mellitus: Epidemiologic complexity and clinical challenge. Periodontol 2000 2018; 78:59-97.

23. Nascimento GG, Leite FRM, Vestergaard $P$, Scheutz F, López R. Does diabetes increase the risk of periodontitis? A systematic review and meta-regression analysis of longitudinal prospective studies. Acta Diabetol 2018; 55: 653-667.

24. Nociti FH Jr, Casati MZ, Duarte PM. Current perspective of the impact of smoking on the progression and treatment of periodontitis. Periodontol 2000 2015; 67:187-210.

25. Bergström J, Eliasson S, Dock J. A 10-year prospective study of tobacco smoking and periodontal health. $J$ Periodontol. 2000; 71: 1338-47.

26. Faddy MJ, Cullinan MP, Palmer JE, Westerman B, Seymour GJ. Ante-dependence modeling in a longitudinal study of periodontal disease: the effect of age, gender, and smoking status. J Periodontol 2000; 71:454-9.

27. Needleman I, McGrath $C$, Floyd P, Biddle A. Impact of oral health on the life quality of periodontal patients. $J$ Clin Periodontol. 2004; 31:454-7.

28. Furuta M, Ekuni D, Irie K, Azuma T, Tomofuji T ve ark. Sex differences in gingivitis relate to interaction of oral health behaviors in young people. J Periodontol 2011; 82: 558-65. 